\title{
Eating oysters, naked: realizing critical architectural discourse
}

\author{
"Les Extrêmes Qui se Touchent?"/’Les Extrêmes Qui se Touchent" is a twice- \\ published paper authored by prominent Canadian theorist-architect George Baird. In \\ both its original journal and reissued edited-book forms, the paper discussing The \\ Office for Metropolitan Architects (OMA) features a figure drawn by OMA founding \\ member, Madelon Vriesendorp. The figure, "Eating oysters with boxing gloves, \\ naked", depicts two males. The autobiographical introduction heading the edited-book \\ version of the paper reveals the two males in the figure are the author, Baird, and the \\ key subject, Rem Koolhaas. "Eating oysters with boxing gloves, naked" is most \\ remarkable due to the fact that, as the title of the drawing implies, Baird and Koolhaas \\ are figured without clothes. This paper presents a pains-taking formal analysis of the \\ picture, before reviewing conceptions of the term "critical" in architectural discourse, \\ and interrogating the way in which the inclusion in a paper of a drawing of its author, \\ naked, and in the presence of his paper's subject, can result in "criticality". The paper \\ extends its findings to present a theory in relation to historiography, and pertinent to \\ architectural writing and textuality.
}

Keywords: architectural discourse; figures in architecture; figures and personas in architectural culture; George Baird; Rem Koolhaas; The Office for Metropolitan Architects (OMA)

Subject classification codes: 30.010 Academic Architecture; 30.012 Architectural History; 30.015 Architectural Theory.

“Les Extrêmes Qui se Touchent?”, written by George Baird, was published in the 1977 special issue of Architectural Design on OMA (The Office for Metropolitan Architects). ${ }^{1}$ The first page of the paper features a drawing that covers around forty percent of the surface area. The figure is captioned, “"Eating oysters with boxing gloves, naked' - OMA's puritanical hedonists: 'somewhat Corbusian Supermen, nonchalant in their ongoing confrontation with metropolitan destiny ....".2

1. George Baird, “Les Extrêmes Qui se Touchent?”, AD 47:5 (1977): 326-327.

2. Baird, "Le Extrêmes Qui se Touchent", 326. 
Baird re-published the article, including the figure, as a chapter in his 2015 book, Writings on Architecture and the City. ${ }^{3}$ In this later publication, the figure is somewhat reduced in size and prominence (filling around a quarter of the second page), slightly cropped on the right-hand side, and captioned, "Cover image from Architectural Design, volume 47, no 5, showing Vriesendorp's drawing, Oysters With Boxing Gloves, Naked."4 The "Vriesendorp" in this caption refers to Madelon Vriesendorp, one of the founding members of OMA.

This paper investigates the significance of Vriesendorp's drawing. The paper's central focus is discrete: the impact of "Eating oysters with boxing gloves, naked" on the Baird's texts - the journal article "Les Extrêmes Qui se Touchent?", and the book chapter "Les Extrêmes Qui se Touchent”. The paper contains four parts. First, it analyses the figure formally. Second, it details the framing Baird gives of the figure in Writings on Architecture and the City; his account of the background to, and contexts of, its construction. Third, it discusses conceptualisations of authorship and author-subject relevant to the practice of architectural criticism, and the concept of "critical" in architectural discourse. Fourth, it presents an argument that characterizes the effect of "Eating oysters with boxing gloves, naked". By its conclusion, the paper will extend beyond its central concern to make postulations of historiographic relevance, suggesting a theory pertaining to the practice of writing "critical" forms for architectural discourse.

\section{Puritanical hedonists}

"Eating oysters with boxing gloves, naked" occupies the bottom left-hand corner of the verso

3. George Baird, "Les Extrêmes Qui se Touchent," in Writings on Architecture and the City (London: Artifice, 2015), 161-164.

4. Baird, "Les Extrêmes Qui se Touchent," 163. The image occupies the first page of the article as described, but is not the cover of the journal issue, as this caption seems to suggests. 
page 326 of $A D 47: 5,1977$. The medium is unspecified. The quality of the rendering suggests graphite on paper. The drawing is bordered by a single line rectangle, set off the left and bottom margins. Like all the pages of the article and the issue, the page layout is based on three columns. The figure fills the extent of two columns in width. The rectangular frame is slightly wider than $4: 3$, thus wider than the golden ratio. The figure is headed by the name of the paper's author, rendered in full capitals - GEORGE BAIRD - and the title, in mixed case. Both name and title are rendered in a large font, in a very heavy bold.

A large proportion of the drawing is white space. The image can be very roughly divided into six: into two quite even halves, with a vertical division extending up from the edge of the apparently table-cloth-covered table (or, less-likely, solid plinth) that occupies the bottom left-hand corner of the frame; and three horizontal thirds, the lowest established by the back edge of the horizontal face of the table (the surface supporting the plate of five irregularly-shaped, furrowed objects that the title suggests are oysters - apparently unshucked, as the meat is not articulated); the uppermost defined largely by what appears to be a ceiling. The sixth occupying the top right-hand corner of the drawing is mostly white space; the sixth occupying the middle of the left-hand column is most densely shaded, and most heavily contrasted.

The image depicts an internal space. The ostensible ceiling meets walls on the lefthand side and rear of the space, and extends over a vertical plane extending back to a vanishing point around halfway up and two-thirds to the right of the frame. The regular vertical divisions of this plane suggest the front surface of a row of lockers; a row of lowerthan-mid-height marks extending along this block to another vanishing point suggests locks. A continuous element runs adjacent to the lockers, though not in parallel (again extending to its own vanishing point). This appears to be a bench, though its horizontal plane seems far below conventional bench height, and its width far too narrow to allow comfortable seating. 
Two vague objects on the bench do not clarify the element. ${ }^{5}$ Taking guidance from the reference to the metropolis in the caption, the image can be understood to depict a locker room in an athletic club.

In addition to the aforementioned plate of five oysters are three human figures. The most peripheral dog-ears the bottom left-hand corner of the frame. A pair of what appear to be y-front jockeys cover (or, perhaps, a jock-strap emphasizes) the buttocks of a bent-over male. The cleft between the cheeks of the buttocks is heavily rendered. The small portion of legs below, and the sloping surface of the back above, extend to the left-hand and bottom edges of the frame, respectively. While the drawing does not quite show this explicitly, it appears to be a male leaning his elbows on the table.

The other two figures in the drawing dominate the image. The male figure on the left, whose legs are obscured by the table, is, bar the tip of his left elbow, contained within the left half of the image. The male figure on the right is standing clear of the table, and, bar his two boxing-gloved hands, is contained within the right half. The gloved left hand of the right-hand figure and the gloved right hand of the left-hand figure both rest on the table, ostensibly touching (though it could be argued that this appearance was the result of foreshortening). The gloved left hand of the left-hand figure and the right hand of the right-hand figure hold what appear to be oyster shells. The oyster shell in the gloved hand of the figure on the left seems to have released its meat. A fleshy piece of matter is pictured falling into the quitetightly-open mouth of a strong jaw. The oyster being held by the figure on the right is poking up from the glove, on display just above and to the left of the centre of the image.

Ostensibly mid oyster-ingestion, the male figure on the left is quite heavily muscled. His pectoral muscles hang over his ribcage; his right deltoid and bicep are outlined and

5. If the image is related to Vrisendorp's "Flagrant Delit" here, as later in this paper, these objects might be associated with the Goodyear blimp condom. 
shaded to give the appearance of roundness; and his head appears to attach awkwardly to his shoulders, his neck not finely articulated, and rather heavily rendered. The brow of this figure is prominent, the supraorbital ridge pronounced and sloping in the manner of a Neanderthal. His fixed expression approaches a scowl. The hair is cut short in a style befitting the military, and the face is beardless. The eyes are deep-set, and the chin completing the robust, rounded jawline sports a heavy cleft. The shading around his right arm and shoulder is dark, denoting muscularity; and this general tone shadows his character. The overall impression is one of a tough, brawny man.

Ostensibly mid enunciation, the male figure on the right, while robust, is less heavily muscled. The deltoids, pectorals, and bicep visible are full without being pronounced. The more angular face is held by a slightly more delicate neck, the eyes less deep-set, and - by virtue of his less acute brow and his teeth-baring, perhaps smiling mouth - the facial expression seems more relaxed. Again, this figure is cleanly shaven, and his hair is short (though in this case, the military issue is slightly corrupted by a teddy-boy or rocker style). His posture - the propping of the oyster, the relaxed bend to his left leg, the slight downward tilt of his head - and the lower density of graphite bordering his body gives him a more relaxed, light air.

While the absence of visible pupils means a definitive judgment about the directions of their gazes is impossible, the angles of the heads of the two men suggest they are regarding each other. The aforementioned dynamic mouth of the right-hand figure, and the enframed ear of the left-hand figure also suggest a conversation - or at the very least, a received monologue.

The two figures' forms are articulated around the boxing gloves that cover their hands. While pugilism would not be out of place in the contexts of an athletic club, it is difficult, in the scenario depicted in the image, to see the gloves as remnants of previous exertions or 
signifiers of future exercise. Indeed, despite the gloves, the reader seems vindicated to rule boxing out of the reckoning. In addition to protective equipment, high impact physical exercise is conventionally undertaken wearing regulative clothing - if not a singlet and shorts, then at least a leotard, or compression shorts. This is not mere tradition or timidity; there are practical reasons: to restrict the disagreeable movement of sensitive body parts. While the two figures are not entirely visible, the parts in view suggest they are naked. The title reinforces this suggestion. With the graphic information provided, it seems logical to assume that the two figures never paired singlets or compression shorts or the like with boxing gloves: it is difficult to see how they could remove these items of clothing while remaining gloved. Boxing gloves are conventionally and almost by necessity the last pieces of attire to be put on, and the first to be taken off.

The obvious conclusion is that the figures gloved themselves while naked. Despite the obviousness of this conclusion, the logic behind such a suggestion remains tenuous. It is almost impossible to imagine anyone eating oysters wearing boxing gloves: the padding of this safety equipment dramatically reduces dexterity to the point where picking up an oyster in its shell, and sliding its meat into a mouth, would be extremely challenging.

Such logical challenges do not, however, trouble readings of the image. The practicalities of the gloves are not at stake in the drawing. Wearing boxing gloves and nothing else while eating oysters is unquestionably irrational. The drawing requires this to be so. It frames the activity as incongruous and thereby positions the gloves as symbolic, figurative. Idiosyncrasy - wearing boxing gloves but being otherwise naked - and awkwardness - eating oysters wearing boxing gloves - both help shift focus from pragmatics to poetics.

The poetic aspect of the gloves in the image is metonymically applied to the figures depicted. The gloves characterise the two men as determined - at least at that depicted moment - by their irrational natures. The lack of adherence to convention and/or lack of 
regard for efficiency demonstrated by the two figures justifies the caption's classification of them as "hedonists". They are not sensible, but rather sensual; not athletes, but rather aesthetes.

While the figurative boxing gloves help establish the characters of the two men engaged in conversation, they do not establish the nature of their relationship. This can be construed from their body positions. The apparent touching of the right-hand figure's gloved right hand and the left-hand figure's gloved left hand on the table implies a level of intimacy. The extreme adjacency of the right-hand figure's gloved right hand to the left-hand figure's ribcage, and the arching of the left-hand figure's body to expand said ribcage, helps develop this impression. If the oyster in the hand involved were removed, one might see the glove landing a short uppercut. The casualness of both figures despite this level of physicality suggests a shared comfort with vulnerability: the left-hand figure is allowing himself to be physically exposed, defenceless; the right-hand figure is jocularly playing with this level of openness - with his potential effect.

The most conspicuous element of the drawing, the punctum of the text, ${ }^{6}$ is the penis of the figure on the right-hand side of the page. Sited beneath a thatch of pubic hair, it is scaled somewhere between the member possessed by Michelangelo's David, and those of the police, sailors, and bikers drawn by Tom of Finland. ${ }^{7}$ It is neither erect nor entirely flaccid. It shows some subtle engorgement. It is the type of engorgement associated with either a nonescalating and muted level of sexual excitement, or a transitional state - on the way up to, or on the way back from, a full erection. It is colloquially referred to as a semi. An enshadowed

6. The use of this term follows Roland Barthes.

7. Legal name Touko Valio Laaksonen. Tom of Finland drawings gained mainstream popularity during the 1970s. 
scrotum sits behind the penis, the corona, glans, and urethral opening of which suggests circumcision.

The right-hand figure's semi adds an erogenous aspect to the sensual hedonism characterising both men, and the physical relation they share. Reinforced by the reputedly aphrodisiacal oysters, the punctumal member suggests the image depicts an erotic encounter. The figurative gloves can be taken to contribute to the scenario in a fetishistic, or even sadomasochistic manner.

A reading of the drawing's characterisation of the figures as pleasure-seeking and/or pleasure-taking, and of their relation as intimate and erotic, leads to metonymic extensions. Padded-gloved-hands allude to masturbation or manual sex. Swallowing oysters suggests the intraoral completion of fellatio. The protruding buttocks of the only-partially-seen third figure in the image insinuate anal sex. Taking all of the connotative dimensions into consideration, "Eating oysters with boxing gloves, naked" works to position its two central figures in relation to homoeroticism.

The image's caption implies quite strongly that its two main figures are "OMA's puritanical hedonists". A casual knowledge of the Office for Metropolitan Architecture in the late 1970s could lead one to imagine the two figures represent its two male members, Rem Koolhaas and Elia Zenghelis; or perhaps Koolhaas or Zenghelis and Oswald Mathias Ungers, the group's mentor and theory reference point. Despite the lack of semblance between the two figures and any of these candidates, readers of $A D$ could have justifiably assumed such a pairing. However, the words Baird uses to frame "Les Extrêmes Qui se Touchent" as a "Critical Biography" thirty-eight years later construct an entirely different scenario.

\section{Somewhat Corbusian supermen}

"Les Extrêmes Qui se Touchent" was republished in the "Critical Biography" section of Writings on Architecture and the City. It is the first of four chapters in "Part 1: Rem 
Koolhaas, OMA, and some other Dutch Architects", the others chapters being "OMA, NeoModern and Modernity”, 2001; “Review of Mart Stam's Trousers by Crimsom, with Michael Speaks and Gerard Hadders”, 2001; and “An Open Letter to Rem Koolhaas”, 2007. ${ }^{8}$

The re-presented paper is prefaced by a short introduction. In this introduction, Baird sketches out the backstory to the paper's construction. In a "large apartment" on London's Wimpole Street, Charles Jencks - Baird's "friend" and former collaborator - introduced Baird to "a new friend of his, a young Dutch student at the Architectural Association School, called Rem Koolhaas." " Baird suggests Jencks "looked forward with some anticipation to strenuous theoretical arguments between [Baird] and Koolhaas"; but "such arguments never really materialised." ${ }^{10}$ Instead, Baird "became friends with both Koolhaas and his wife, Madelon Vriesendorp." ${ }^{11}$ Several years later, Koolhaas and then- $A D$ editor Haig Beck presented Baird with "a sudden - and spontaneous - invitation ... to make a contribution" to the special issue on OMA that was, at the time, receiving its "finishing touches". ${ }^{12}$ Baird accepted the invitation; and "literally overnight" - he tells his reader that "Peter Eisenman later told [him] that he would never accept such a risky, rapid writing assignment"13 - he completed "Les Extrêmes Qui se Touchent?”. ${ }^{14}$ Then, “[i]n response to [his] effort”, “over a second night”, Koolhaas's then-wife and fellow OMA member Vriesendorp "made the drawing of two athletes 'eating oysters naked with boxing gloves", ${ }^{15}$ that features on the journal article's first

8. The other three Parts discuss the works of Ignasi de Solà-Morales, Colin Rowe, and Joseph Rykwert.

9. Baird, "Les Extrêmes Qui se Touchent", 161.

10. Baird, "Les Extrêmes Qui se Touchent”, 161.

11. Baird, "Les Extrêmes Qui se Touchent", 161.

12. Baird, "Les Extrêmes Qui se Touchent", 161.

13. Baird, "Les Extrêmes Qui se Touchent", 162.

14. Baird, "Les Extrêmes Qui se Touchent", 162.

15. Baird, "Les Extrêmes Qui se Touchent”, 162. 
page, and the second of "Les Extrêmes Qui se Touchent" - albeit in reduced size. Baird then adds an anecdotal aside: he claims, "[o]nly later did I come to realise that the witty Vriesendorp drawing was actually of Koolhaas and me."16

Baird's introduction adds an additional and rather consequential layer of meaning to "Eating oysters with boxing gloves, naked". The hair and physiques of the two figures do not readily equate with Baird and Koolhaas in 1977: photographs suggest both men sported the mid-length, floppy hair that was popular at the time; and neither man was well muscled Baird appearing of medium build, and Koolhaas lean, or even skinny. Nevertheless, most readers prepared by the introduction to "Les Extrêmes Qui se Touchent" to see Baird and Koolhaas in the forms of the image would see the left-hand figure as the former, and the righthand figure as the latter: the brow ridge, jaw line and cleft chin of the left-hand figure bear a modest likeness to Baird; the long nose on the right-hand figure vaguely points to Koolhaas.

The reading of the image as representing Baird and Koolhaas respectively not only makes the left-hand figure the author of the paper, but also the right-hand figure the key subject of the paper, and the husband of the artist that produced "Eating oysters with boxing gloves, naked". This has some significance in relation to that figure's previously noted semi. ${ }^{17}$ While the lack of realism in relation to the physiques of the two men places some doubt over the life-likeness of the penis, the artist's presumed association with her husband suggests the semi could be loaded with meaning. If the symbolic boxing gloves are seen as referencing the "strenuous theoretical arguments" that Baird claims Jencks anticipated, a clear interpretation arises: the partially-engorged penis stands for a latent physicality, a sexual tension, held between Baird and Koolhaas.

16. Baird, "Les Extrêmes Qui se Touchent”, 162.

17. For contrast, see Kenneth Colburn Jr., "Desire and Discourse in Foucault: The Sign of the Fig Leaf in Michelangelo's 'David'," Human Studies 10:1, "Foucault Memorial Issue" (1987): 61-79. 
Seeing the two figures in Vriesendorp's image as the author of "Les Extrêmes Qui se Touchent?"/“Les Extrêmes Qui se Touchent” and a key object of that paper, and viewing the state of the latter's penis as subtly but persistently engorged, has considerable impacts. It provokes many questions, both specific and general. This current paper will pursue a question significant to the practice of architectural criticism: is it possible for someone engaged in an erotic relation with another party to write a critical piece on that second party's firm? ${ }^{18}$

\section{Nonchalant in their ongoing confrontation}

Common sense understandings would see a paper written by someone depicted as naked, gratuitously indulging their senses, and in the presence of, if not the stimulation for, a partially engorged penis in the only illustrative figure within that paper, as incapable of attaining any degree of criticality. Baird's inclusion in Vriesendorp's image implicates him in both the production and construction of the content under discussion and supposed analysis. He is a "somewhat Corbusian superman", according to the caption included in the paper.

This common sense is supported by the academy. In their paper "The Judge is Not an Operator: Historiography, Criticality and Architectural Criticism”, John Macarthur and Naomi Stead frame the conventionally-acceptable critic as "a judge who ... requires some authority to stand outside the present." ${ }^{19}$ They assert criticism contends with "age-old perceptions of bias" by offering "judgment without operation in and of itself". ${ }^{20}$ Clearly, while it may involve objectifications, an erotic relationship such as that depicted in "Eating

18. Or perhaps, "semi-firm": OMA was, at the time, four individuals, without significant commissions.

19. John Macarthur and Naomi Stead, "The Judge is not an Operator: Historiography, Criticality and Architectural Criticism”, OASE 69 (2006): 128.

20. Macarthur and Stead, "The Judge is not an Operator", 118 (the authors pair "bias" with "timidity", but this adjective seems less applicable in this case); 118. 
oysters with boxing gloves, naked" does not offer ideal conditions for attaining distance or disinterest; and being involved in such a liaison advances charges of bias.

Restrictions of claims to a "critical" position built upon Baird's seemingly very personal involvement with one of the key protagonists from the firm about which he writes are amplified by elements of the preface Baird gives to "Les Extrêmes Qui se Touchent”. The autobiographical narrative undermines the ability of Baird to "stand outside the present" and thus judge without operating. ${ }^{21}$ The remarkably compressed timeline within which the essay was purportedly completed disrupts the author's claims to authority: the more time-sensitive the writing task of "Les Extrêmes Qui se Touchent?", the more inescapable the present-ness of the undertaking seems. From this perspective, Eisenman's reported assessment of risk might be seen as less driven by performance anxiety, and more by conceptual inaccessibility. Further, through accident or intention, the introductory passage includes a series of connotations to erotic and sexual behaviours: Jencks "look[ing] forward with some anticipation to strenuous theoretical arguments" suggests voyeurism, a kind of homoeroticism focused on sweaty wrestlers; far more insidious, "a new friend ..., a young Dutch student" insinuates a vaguely menacing affiliation between Jencks and Baird based on grooming; more palpable, despite Baird's claims that it was unintentional and the result of linguistic incompetence, "extremes qui se touchent" alludes to masturbation; ${ }^{22}$ and, most graphic, applying the phrase "finishing touches" to Koolhaas clearly implies ejaculation. Koolhaas's involvement in the solicitation of the essay for the journal special edition on his firm places the independence of Baird's authorship in further doubt. A scathing assessment might relate

21. This provokes a question: could Baird or any other author write a "Critical Autobiography"? 22. Baird himself gives this meaning: "in my haste, and due to my shaky command of the French language, I mistakenly wrote for the title the phrase 'extremes qui se touchent', as opposed to 'extremes qui touchent' thus unintentionally evoking masturbation" (162). Even the word "shaky" alludes to hands. 
the situation to ghost-writing, and look for a figurative hidden hand animating a puppet; or even liken the special edition of the reputable journal $A D$ to the vanity press. Extending this critique, the depiction of "Eating oysters with boxing gloves, naked" might be characterized as OMA-head Koolhaas indulging Baird, feeding him luxurious delicacies and possibly complements in immoderate contexts, thereby buying favour and sympathetic commentary.

Given these rather glaring issues, it is a wonder that Baird chose to republish the image, elaborate the contexts of its constructions, and provide a denotation of its form, in his auto-festschrift-like volume. Rather than a reduction in size, Vriesendorp's image might simply have been edited out of the paper, along with the question mark in the original title. "Eating oysters with boxing gloves, naked" could have been consigned to history - left as a textual oddity. But such a reading assumes conventional common sense. It assumes a discursive formation that frames a certain type of authorial subject. Architectural discourse provides an alternative framing.

Around the time that "Les Extrêmes Qui se Touchent?" was written, the word "critical" was gaining an entirely new and discursively powerful significance. According to Macarthur and Stead, it "took on a talismanic character," and was "employed as a kind of charm $[\ldots]$ to both pre-empt and ward off a whole range of (sometimes contradictory) accusations: of commodification, of irrelevance, of empty formal experimentation, of the submission to fashion and spectacle, and so on." 23 "Critical" was a kind of cure-all.

The primary locus of the redefinition of the term "critical" was the New-York-citybased Institute for Architecture and Urban Studies. Suzanne Frank's “insider's memoir” of the IAUS frames its practice as a dialectic: a deliberate and prolonged argument conducted by

23. Macarthur and Stead, "The Judge is not an Operator", 117. 
a group of insiders. ${ }^{24}$ The primary protagonists were founders Peter Eisenman, Kenneth Frampton, and Mario Gandelsonas. Carter Wiseman asserts Eisenman established the IAUS to bring about a "discourse" on architecture and urban studies. ${ }^{25}$ The title of the IAUS's

journal, Oppositions, advertises the nature of that discourse: confrontational and resistant. The inaugural logo of the IAUS, incorporating Cesariano’s "Vitruvian Man" (1521), ${ }^{26}$ reinforces this message with visual coding. The gridded background, the set-at-star-jump position of the man, and the again punctumal penis - on this occasion, pointed upwards, arguably rampant guardant but probably not $\operatorname{erect}^{27}$ - are all contrastive with Leonardo da Vinci's more recognizable drawing. Discernible in the logo is Eisenman's relation to humanism, an antagonism robustly articulated in his 1976 journal article, "Post-functionalism". ${ }^{28}$ While the nature of his discursive outputs has changed in the fifty years since the founding of the

24. Suzanne Frank, IAUS: An Insiders Memoir (Bloomington: Author House, 2010), 185. While Koolhaas was an IAUS Fellow while he was working on Delirious New York, Baird's relation with the Institute was complicated by the work and position of IAUS members Diana Agrest and Mario Gandelsonas, who published an attack on Baird's semiological theories of architecture in the first issue of Oppositions. An interesting side note: Suzanne and her husband Dick commissioned Eisenman to design their house; the result was House VI, famous for the marital bed divided by a glass strip.

25. Carter Wiseman, Twentieth Century American Architecture: The Building and Their Makers (New York: W.W. Norton, 2000), 246. Quoted in Suzanne Frank, IAUS: An Insider's Memoir, 185.

26. The image had been printed previously in Rudolf Wittkower's Architectural Principles in the Age of Humanism (1949) - see Frank, IAUS: An Insider's Memoir, 7.

27. A confident reading of the penis in the IAUS logo is difficult to realise. The man might be lying on his back, or standing. If the former, the penis might be resting on the body; if the latter, the penis would be somehow resisting gravity. While the man's feet are drawn at an angle that appears capable of bearing the weight of the body, and the heavy rendering of the groin area introduces an unhelpful indistinctness, the size of the penis and articulation of its segments seems more likely to imply the former.

28. Peter Eisenman, "Post-Functionalism," in Oppositions 6 (Autumn 1976): i-iv. 
Institute, Eisenman has been consistent in his positioning of "critical" work as that in which "the message itself [is] the interference." 29

A more generous and expansive definition of the term "critical" was offered by Botond Bognar in "Toward an Architecture of Critical Inquiry". ${ }^{30}$ For Bognar,

[a] critical project ... has the incessant task of exposing, demythifying 'self-evident' and 'stable' totalities or the petrified 'idols of the market', while aiming at the same time at another, more sensible 'form' of reality which could afford within its scope the unique dimension of 'le poetique'. ${ }^{31}$

In Bognar's "critical project", there is a double action: the breaking down of old, stale meanings, exposing common sense understandings as mythical; and the construction of new messages that are imbued with more open and generative meanings.

This paper is not interested in reviving the anachronistic and irreconcilable debate between common sense and critical thought. Nor is it motivated by reinvigorating "critical" culture. Rather than rehearse the "dialectic", either theoretically or historically, the goal here is to find historiographic significance. With the help of Eisenman and Bognar's definitions, and the tenets of common sense, the example suggests a different approach to the intellectual history of the period.

29. Peter Eisenman, "Autonomy and the Will to Critical," Assemblage 41 (April 2000): 90. "The critical," Eisenman writes, "begins with the becoming unmotivated of the sign, the potential reduction of the culturally sedimented meaning of signs, so that the message itself becomes the interference. It is interference as foreground and not background that begins to define a fundamental characteristic of the processes of what is, for me, a necessarily existent critical project in architecture"; and "architecture's criticality [...] is the possible articulation of dynamic processes of difference between being and sign within architecture itself."

30. Botond Bognar, "Toward an Architecture of Critical Inquiry," Journal of Architectural Education 43:1 (Autumn 1989): 13-34.

31. Bognar, "Toward an Architecture of Critical Inquiry," 23-24. 


\section{Metropolitan destiny}

It is difficult to see "Les Extrêmes Qui se Touchent?”/“Les Extrêmes Qui se Touchent” as resistant or confronting after its author is identified as one of the central figures of "Eating oysters with boxing gloves, naked", and a key subject is identified as the other. When that same author establishes these identifications himself, it is even more challenging. It is almost impossible to see this author Baird liberated from the Object of Desire of discourse. More readily evident are readings of complicity; of facilitation - of desires gastronomic, carnal, and professional; of upholding, succumbing, or at least stimulating, Objects of Desire. With the identification secured, the article/chapter seems too personal, too invested in latent libidos. There is, however, a path with which "Eating oysters with boxing gloves, naked" can be understood as endowing "criticality" to the texts of which it is a part.

The necessary first step is the removal of the contextual and biographical aspects of the capital-A author from “Les Extrêmes Qui se Touchent?". This is not only an easy move, but arguably an historically appropriate one: Barthes's "Death of the Author" - first published in 1967, republished in 1977 - established a conceptual framework; and many "critical" theorists followed. ${ }^{32}$ Once the author Baird is distanced from the text, "Eating oysters with boxing gloves, naked" illustrates not a compromising hedonism, but rather an awareness of the "gratifications of libidinal language". ${ }^{33}$ The figure acknowledges the existence of persona figures within architectural discourse; and it imparts this acknowledgement onto the accompanying body of writing.

32. See Roland Barthes, "Death of the Author" in Aspen: The magazine in a box (1967) and later in Image-Music-Text (London: Fontana, 1977), 142-148. It is pertinent to note, here, that IAUS members Agrest and Gandelsonas studied under Barthes in Paris, before arriving in New York.

33. Bognar, "Toward an Architecture of Critical Inquiry," 25. 
The representational nature of "Eating oysters with boxing gloves, naked" - its aforementioned lack of realism - reinforces the figural significance. Vriesendorp's work has been related to the Paranoid Critical Method, ${ }^{34}$ and it is indeed possible see "Eating oysters with boxing gloves, naked" as representative of Vriesendorp's subconscious - the work of a wife haunted by thoughts of her husband's faithlessness and/or sexuality; a fleshier reiteration of "Flagrant Delit", the drawings of the Chrysler and Empire State buildings "caught in the act" of sex by the Rockerfeller Center (or, given the deflated Goodyear Blimp condom hanging limply over the edge of the bed, immediately after the act) that were used by Koolhaas as the cover image for Delirious New York $(1978)^{35}$ - or as a conscious work, intending to communicate infidelity and/or deviance. But "criticality" comes from a version of the figure far more abstractly related to this turgid, putative marital saga - one that credits Vriesendorp with an appreciation for the discursive formation to which she contributed and within which two naked men forever stand. Just as she actively removes flesh from her biological then-husband as she constructs a beefed-up "somewhat Corbusian" persona, Vriesendorp brings about her own authorial death. Counterintuitively, her use of a biographical object significant to her own life allows this process. The more implicated Vriesendorp seems to be, the more she, as a biographical agent, achieves distance.

The effect is redoubled in "Les Extrêmes Qui se Touchent”. If Baird is considered to be controlling the entire text (including the figure), and as accepting the "Baird" persona illustrated in "Eating oysters with boxing gloves, naked", a complex kind of criticality can be extracted. ${ }^{36}$ Baird is then implicating himself in the problem of "critical" discourse. He, too, is

34. See Charles Jencks, "Madelon seeing through objects" in The World of Madelon Vrisendorp: Paintings/Postcards/Objects/Games, edited by Shumon Basar and Stefan Trüby (London: Architectural Association Publications, 2008).

35. The drawings were animated by Teri Wehn-Damisch.

36. The figure realises a pun: Baird = bared. 
effecting an abstract separation of biography from text: a self-inflicted death-of-the-author. In this scenario, "Eating oysters with boxing gloves, naked" sets up a kind of mise en abyme in which the figure of the author constantly recedes; "a 'dialectic' with the continuous postponement of synthesis." 37

In the original, “Les Extrêmes Qui se Touchent?”, "Eating oysters with boxing gloves, naked" realises irony - the persona-fication of the author. This critical text uses its own materiality to disrupt the message and possible reception of architectural discourse. In the reprint, "Les Extrêmes Qui se Touchent", the introductory narrative adds parody - of critical writing, and of the self. This critical text makes an overt presentation of "biographies"” tendency to collapse distance between author and subject, exemplifying - in a possible case of discursive masochism - an "author" forgoing personal and professional respectability in favour of publishing a shrunken penis.

\section{Shucking}

Whether through the complex conditions of its production, or the even-more complex dynamics of its construction (and re-construction, and ongoing construction), "Eating oysters with boxing gloves, naked" can be seen to afford "Les Extrêmes Qui se Touchent?"/“Les Extrêmes Qui se Touchent" with criticality. With or without Baird's awareness and complicity, Vriesendorp's drawing introduces a discursively-located dialectic.

The graphic nature of this example is at risk of dominating the significance of this discussion. The ostensibly-gratuitous penis might be a distraction. It might encourage casespecific meanings to arise. Those supportive of common sense might argue that it is the text's apparently wilful avoidance of that mode of thought that gives it a "critical" position, and continue to refuse valuing that use of the term. They might not see any significance, beyond

37. Bognar, "Toward an Architecture of Critical Inquiry," 26. 
an uncontrolled textuality. Those supportive of critical thought might argue that it is the radicalism of the text's "noisy", "poetique" imagery that gives it a "critical" position. They might continue to valorise and overemphasise the term.

However, this case presents more than a new rendering of an idiosyncratic discursive object. The finding suggests a point of broad historical historiographic significance; namely, that the more an author can be distanced from themselves - the more an author can be converted to a persona in the text for which they retain nominal authorship - the more they can be accepted as judge. The more Baird is "George Baird", the more he is a critic. The more a paper is framed as a "Critical Biography", the more decisive is its figural dimension.

Aligning common-sense and critical viewpoints, a chorus is established: the Critic is not an Author. While we are, for better or worse, currently still languishing in a period where the scabs of "critical" theory have not yet fully healed over, this chant should be of significance to contemporary critics seeking to make effective impacts on architectural discourse. 


\section{Reference list}

Baird, George. “Les Extrêmes Qui se Touchent?,” Architectural Design 47:5 (1977): 326327.

Baird, George. "Les Extrêmes Qui se Touchent.” In Writings on Architecture and the City, 161-164. London: Artifice, 2015.

Barthes, Roland. 1977. "Death of the Author." In Image-Music-Text, 142-148. London: Fontana, 1977.

Bognar, Botond. "Toward an Architecture of Critical Inquiry." Journal of Architectural Education 43:1 (Autumn 1989): 13-34.

Colburn, Kenneth Jr. "Desire and Discourse in Foucault: The Sign of the Fig Leaf in Michelangelo’s 'David'.” Human Studies 10:1, “Foucault Memorial Issue” (1987): 61-79.

Eisenman, Peter. "Post-Functionalism.” Oppositions 6 (Autumn 1976): i-iv.

Eisenman, Peter. "Autonomy and the Will to Critical.” Assemblage 41 (April 2000): 90-91.

Frank, Suzanne. IAUS: An Insiders Memoir. Bloomington: Author House, 2010.

Jencks, Charles. "Madelon seeing through objects." In The World of Madelon Vriesendorp: Paintings/Postcards/Objects/Games, edited by Shumon Basar and Stefan Trüby. London: Architectural Association Publications, 2008.

Macarthur, John, and Naomi Stead. "The Judge is not an Operator: Historiography, Criticality and Architectural Criticism." OASE 69 (2006): 116-138.

Wiseman, Carter. Twentieth Century American Architecture: The Building and Their Makers. New York: W.W. Norton, 2000. 